Recepción: 07 / 09 / 2016

Aceptación: 16 / 02 / 2017

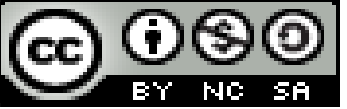

Ciencias de la salud

Publicación: 20 / 08 / 2017

Artículo Original

\title{
Prevalencia del estado parodontal en paciente portadores de prótesis parcial
}

\section{Prevalence of parodontal status in patients with partial dentures}

Prevalência do estado parodontal em pacientes com próteses parciais

\author{
Juan Oliveira del Rio ${ }^{\mathrm{I}}$ \\ juanoliveiradelrio@hotmail.com \\ Sandra Sandoval Pedaya II \\ sandrasando.peya@hotmail.com \\ Freya Andrade Vera ${ }^{\text {III }}$ \\ freya.andrade.@hotmail.com
}

Correspondencia: juanoliveiradelrio@hotmail.com

II

III

Doctor en Ciencias Odontológicas; Docente en la Universidad Laica Eloy Alfaro de Manabí, Manta, Ecuador.

Especialista en Rehabilitación Oral, Odontóloga; Docente en la Universidad Laica Eloy Alfaro de Manabí, Manta, Ecuador.

Especialidad en Periodoncia, Odontóloga; Docente en la Universidad Laica Eloy Alfaro de Manabí, Manta, Ecuador. 


\title{
Resumen
}

Se realizó un estudio descriptivo transversal en el servicio odontológico, con la finalidad de determinar la prevalencia del estado parodontal en paciente portadores de prótesis parcial. La población en estudio estuvo conformada por 50 pacientes. Los criterios que se tuvieron en cuenta fueron: pacientes entre los 18 a 64 años y pacientes portadores de prótesis parcial removible (PPR). La información se recogió en un formulario confeccionado al efecto. En el análisis se encontró mayor prevalencia en la arcada inferior (76.0\%), estado gingival leve (66.0\%), higiene oral deficiente $(40.0 \%)$, ausencia de movilidad $(88.0 \%)$, presencia de retención $(30.0 \%)$. Se encontró relación estadísticamente significativa $(\mathrm{p}<0.05)$ entre las variables higiene bucal y estado gingival. Se concluyó que es de vital importancia realizar controles rigurosos del estado periodontal antes, durante y después de cualquier tratamiento realizado en la cavidad bucal, para garantizar su éxito, funcionalidad, longevidad y por ende bienestar al paciente.

Palabras clave: prevalencia; prótesis dental; parodontal.

\begin{abstract}
A cross - sectional descriptive study was performed in the dental service, in order to determine the prevalence of the parodontal condition in patients with partial dentures. The study population consisted of 50 patients. The criteria that were taken into account were: patients between 18 and 64 years of age and patients with removable partial dentures (PPR). The information was collected in a form prepared for this purpose. In the analysis we found a higher prevalence in the lower arch (76.0\%), mild gingival state $(66.0 \%)$, poor oral hygiene $(40.0 \%)$, absence of mobility $(88.0 \%)$, presence of retention $(30.0 \%)$. A statistically significant relation $(\mathrm{p}<0.05)$ was found between the variables oral hygiene and gingival state. It was concluded that it is vitally important to perform rigorous periodontal state controls before, during and after any treatment performed in the oral cavity, to guarantee its success, functionality, longevity and thus well-being to the patient.
\end{abstract}

Keywords: prevalence; dental prostheses; parodontal

\section{Resumo}

Empresas Um estudo descritivo transversal foi realizado no serviço odontológico, a fim de determinar a prevalência da condição parodontal em pacientes com próteses parciais. A 
população estudada era de 50 pacientes. Os critérios que foram levados em consideração foram: pacientes com idade entre 18 e 64 anos e pacientes com próteses parciais removíveis (PPR). A informação foi coletada em um formulário preparado para esse fim. $\mathrm{Na}$ análise mais prevalente no arco inferior $(76,0 \%)$, estado moderado gengival $(66,0 \%)$, a falta de higiene oral $(40,0 \%)$, ausência de mobilidade $(88,0 \%)$, a presença de retenção $(30,0 \%)$ que foi encontrado. Uma relação estatisticamente significante $(\mathrm{p}<0,05)$ foi encontrada entre as variáveis higiene bucal e estado gengival. Concluiu-se que é de vital importância realizar exames periodontais rigorosos antes, durante e após qualquer tratamento realizado na cavidade oral, para garantir seu sucesso, funcionalidade, longevidade e, portanto, bem-estar para o paciente.

Palavras chave: prevalência; prótese dental; parodontal

\section{Introducción}

El periodonto es un sistema funcional que comprende la encía, ligamento periodontal, el cemento radicular y hueso alveolar, la función principal consiste en transmitir y amortiguar las fuerzas masticatorias, y su capacidad propioceptora ayuda a mantener la integridad en la superficie de la mucosa masticatoria de la cavidad bucal. Constituye una unidad de desarrollo biológico y funcional, que sufre cambios atribuibles a factores como la edad, adicción, alteraciones oclusales y medio bucal. ${ }^{1}$

Las enfermedades periodontales son patologías que afectan al periodonto, es decir, a los tejidos que sostienen y rodean a los dientes, son patologías infecciosas, causadas por bacterias, según el grado de afección puede producir la pérdida total o parcial de los tejidos de soporte dentario. "Considerando que la etiología de la enfermedad es principalmente infecciosa (biofilm), el tratamiento se enfoca fundamentalmente en el control de la infección. ${ }^{2}$

El surgimiento de la prótesis y las lesiones provocadas por esta, es muy antiguo. Al principio los prácticos en dicha materia solo se limitaban a la restauración mecanicista de las piezas perdidas, sin interesarse por la forma integral de estas y sus relaciones con el resto del organismo. Desde entonces se ha recalcado la importancia que tiene la confección de la aparatología de una forma correcta y la necesidad de exámenes periódicos. De ahí que la prótesis deje de constituir un estímulo para los tejidos de sostén y se convierta en una agresión física al medio bucal. ${ }^{3}$ 
Los hallazgos en la literatura con respecto a la PPR y sus repercusiones periodontales presentan resultados desfavorables. En nuestro medio existen pocos trabajos de investigación acerca de este tema, por tal motivo se plantea este estudio, para estar al tanto de las necesidades de atención de dicha población. ${ }^{1}$

Algunos autores han sugerido que el uso de PPR, conduce a cambios importantes en la cantidad y calidad de la formación de la placa bacteriana alrededor de los dientes remanentes. Por otra parte, varios investigadores han concluido que cuando se realiza una buena higiene bucal se presenta poco o ningún daño sobre los dientes remanentes y su soporte periodontal. ${ }^{1}$

De ahí nace la necesidad de investigar el estado periodontal de aquellos pacientes portadores de las prótesis parciales removibles, de tal forma que los resultados obtenidos, puedan ayudar a elaborar normas preventivas con el objetivo de mantener la salud periodontal, y tenga un alcance significativo en odontólogos y estudiantes de odontología.

\section{Metodología}

Se realizó un estudio descriptivo transversal en el servicio odontológico con la finalidad de determinar la prevalencia del estado parodontal en pacientes portadores de prótesis parcial. La población en estudio, estuvo conformada por 50 pacientes.

Los criterios que se tuvieron en cuenta fueron: pacientes entre los 18 a 64 años y pacientes portadores de prótesis parcial removible (PPR).

Entre las variables analizadas figuraron:: genero, edad, arcada, estado gingival, estado de higiene oral, las variables retención, movilidad, recesión y defecto de furcación. Se valorizo en no presenta y presenta, estado de PPR valorizada en bueno (adaptado, sin fractura) y malo (desadaptado, fracturado) y estado periodontal valorizada en sano (estado gingival = leve, estado de higiene $=$ adecuada, para las variables retención, movilidad, recesión y defecto de furcación $=$ ausencia de estas características) y enfermo (estado gingival $=$ moderado o severo, estado de higiene $=$ aceptable o deficiente, para las variables retención, movilidad, recesión y defecto de furcación $=$ presencia de estas características $)$.

La recogida del dato primario, se realizó a través de una planilla confeccionada por el autor. 
Los datos obtenidos fueron procesados, utilizando el paquete estadístico SPSS versión 5.0 y los resultados obtenidos fueron plasmados en un tabal simple. Se utilizó como medida de resumen las frecuencias absolutas.

\section{Resultados}

Tabla. Variable de interés de interés de los pacientes portadores de PPR.

\begin{tabular}{|c|c|c|c|}
\hline Variable & Categoría & No & $\%$ \\
\hline \multirow[t]{2}{*}{ Genero } & Femenino & 43 & 86.0 \\
\hline & Masculino & 7 & 14.0 \\
\hline \multirow[t]{5}{*}{ Grupo etarios } & $20-29$ & 9 & 18.0 \\
\hline & $30-39$ & 8 & 16.0 \\
\hline & $40-49$ & 19 & 38.0 \\
\hline & $50-59$ & 10 & 20.0 \\
\hline & $60-64$ & 4 & 8.0 \\
\hline \multirow[t]{2}{*}{ Arcada } & Superior & 12 & 24.0 \\
\hline & Inferior & 38 & 76.0 . \\
\hline \multirow[t]{3}{*}{ Estado gingival } & Leve & 33 & 66.0 \\
\hline & Moderado & 16 & 32.0 \\
\hline & Severo & 2 & 4.0 \\
\hline \multirow[t]{3}{*}{ Higiene oral } & Adecuada & 8 & 16.0 \\
\hline & Aceptable & 22 & 44.0 \\
\hline & Deficiente & 20 & 40.0 \\
\hline \multirow[t]{2}{*}{ Movilidad } & Presente & 6 & 12.0 \\
\hline & No presente & 44 & 88.0 \\
\hline \multirow[t]{2}{*}{ Retención } & Presente & 15 & 30.0 \\
\hline & No presente & 35 & 70.0 \\
\hline \multirow[t]{2}{*}{ Recesión } & Presente & 19 & 38.0 \\
\hline & No presente & 31 & 62.0 \\
\hline
\end{tabular}

En la tabla se muestra prevalencia del sexo femenino (86.0\%), con respecto al sexo masculino, el grupo de edad de $40-49$, fue de un $38.0 \%$. 
Con respecto a las arcadas más afectada, fue la arcada inferior con un $76.0 \%$, encontrándose mayormente en el sexo femenino. El estado gingival en la clasificación de leve, moderada y severa, el mayor por ciento correspondió a la leve (66.0\%).

Como se muestra en la tabla, la higiene bucal se valoró de adecuada $16.0 \%$ del total de pacientes examinados, la diferencia entre aceptable y deficiente no es significativa (44.0\% y $40.0 \%$ ).

En la serie al examinar la movilidad de los dientes presentes, se observó que el 88.0\% no presentaban este diagnóstico.

Según muestra la tabla, la variable recesión se encontró ausencia $(62.0 \%)$ y presencia (38.0\%). En cuanto al variable defecto de furcación, todo el universo carecía de este defecto. Por otro lado, la variable estado de PPR se encontró en buen estado (26.15\%) y mal estado (74.0\%). La variable estado periodontal, se encontró periodonto sano $(8.0 \%)$ y periodonto enfermo $(84.0 \%)$.

Se encontró relación estadísticamente significativa $(\mathrm{p}<0.05)$ entre las variables higiene bucal y estado gingival.

\section{Discusión}

El uso de las prótesis parciales removibles, puede ser uno de los varios tratamientos de elección para la restauración de rebordes edéntulos parciales. ${ }^{4}$ Aun cuando la prótesis parcial removible (PPR) es un medio para reemplazar dientes perdidos, puede volverse una amenaza para los dientes remanentes o pilares de los pacientes debido a que puede incrementar la incidencia de caries, afecta el periodonto y aumenta la cantidad de fuerzas sobre los pilares. ${ }^{5}$ Estas alteraciones se atribuyen a una higiene oral deficiente, acumulación de la placa bacteriana y acumulación de cálculos. Es posible reducir los efectos negativos de la PPR si se realizan medidas adecuadas de higiene bucal ya que solamente se han notado efectos dañinos menores en pacientes atendidos regularmente. ${ }^{6}$ En esta investigación se halló un alto índice de estas alteraciones.

Es evidente que los pacientes portadores de prótesis dental, con frecuencia son afectados debido a la agresión física que sufren los tejidos bucales, acompañados de otros factores negativos como los traumas y las infecciones. ${ }^{7-8}$ 
Al respecto, son diversos los tratamientos convencionales y tradicionales empleados en las alteraciones bucales asociadas con el uso de prótesis dental, pues dichas alteraciones constituyen trastornos de elevada prevalencia parodontal que resultan cada vez más preocupantes para las autoridades sanitarias encargadas de la salud en la comunidad. ${ }^{9}$

En la bibliografía medica consultada, López Jurado ${ }^{10}$ en su investigación, sus resultados fueron similares a los de nuestra investigación. El 83\% padecía algún tipo de EP, mientras el 17\% se encontraban sanos. En cuanto al género las mujeres se vieron más afectadas (50\%), y según el grupo etario se vieron más afectados los de 40-59 años (57\%).

Con respecto a la arcada comprometida con la PPR, Belaunde ${ }^{11}$, López ${ }^{12}$ y Awuapana ${ }^{13}$, encontraron mayor prevalencia de la arcada inferior, donde existe mayor acumulación de restos alimenticios durante y después de su ingesta. Por otro lado resaltan que la arcada superior es la menos afectada, gracias a la función protectora de la lengua que genera una autolimpieza sobre las superficies dentarias superiores, coincidiendo con la investigación.

Con respecto al estado gingival, la mayoría de estudios que relacionan el estado periodontal y el uso de PPR mencionan resultados generales sin especificar el origen, ni el grado de inflamación. Sin embargo Yeung ${ }^{14}$ y Akaltran ${ }^{15}$, especifican que los conectores mayores, placas proximales y brazos retentivos u opositores favorecen la retención y acumulación de placa blanda, los cuales invaden el tejido de soporte generando características desfavorables a nivel gingival.

Se concluyó que es de vital importancia, realizar controles rigurosos del estado periodontal antes, durante y después de cualquier tratamiento realizado en la cavidad bucal, para garantizar su éxito, funcionalidad, longevidad y por ende bienestar al paciente.

\section{Referencias bibliográficas}

1. Gonzáles G, Chávez-Reategui B, Manrique-Chávez J, Hidalgo-López I. Prevalencia del estado periodontal de pacientes portadores de prótesis parcial removible tratados en una clínica dental privada. 2014 [citado 9 Feb 2017]. Disponible en: https://www.researchgate.net/publication/290600769_Prevalencia_del_estado_periodontal_de_pa cientes_portadores_de_protesis_parcial_removible_tratados_en_una_clinica_dental_privada 
2. Arcentales Torres C, Cuenca Otavalo M. Estado periodontal en pacientes portadores de prótesis removible que acuden a la Facultad de Odontología de la Universidad de Cuenca 2015, [citado Feb 2017]. 92 Disponible dspace.ucuenca.edu.ec/bitstream/123456789/24038/1/TESIS.pd

3. González Heredia E. Aspectos principales de la salud bucal en el adulto mayor en el Consejo Popular Guillermón Moncada. Municipio Santiago de Cuba. Enero-Junio, 2000. Santiago de Cuba: Instituto Superior de Ciencias Médicas; 2000 [citado 12 Sep 2017]. Disponible en: http://www.sld.cu/galerias/pdf/uvs/saludbucal/saludadulto.pdf

4. Ardila Medina C.M. Efectos de la prótesis parcial removible sobre la salud periodontal. Avances en Periodoncia [revista en la Internet]. 2010 Ago [citado 2015 Jul 07]; 22(2): 77-83. Disponible en: http://scielo.isciii.es/scielo.php?script=sci_arttext\&pid=S1699$65852010000200003 \& \operatorname{lng}=\mathrm{es}$

5. Eley B.M., Soory M., MANSON J.D. Periodoncia. Editorial Elsevier. $6^{\circ}$ Edicion. Barcelona. España.2012. págs. 163-166

6. Mulet García M, Hidalgo Hidalgo Siomara, Díaz Gómez S M. Salud bucal en pacientes portadores de prótesis: Etapa diagnóstica. AMC. 2006 [citado 2017 febrero 06]; 10(5): 34-43. Disponible en: http://scielo.sld.cu/scielo.php?script=sci_arttext\&pid=S1025$02552006000500005 \& \operatorname{lng}=\mathrm{es}$

7. Sotomayor T. Alteraciones clínicas de la mucosa bucal en personas de la tercera edad portadoras de prótesis totales. Odontología Sanmarquina. 2012; 1(3):37-42

8. Perrone M. La prótesis odontológica en la ecología de Cándida albicans en cavidad bucal. Acta Odontol Venez. 2011; 39(3):8-24

9. Corona Carpio H, Escalante D, Navarro Nápoles, Ramón Jiménez, y Dra. Lizel Díaz del Mazo. Factores locales y su relación con lesiones bucales en ancianos portadores de prótesis totales. Revista Medisan 2017, [citado 9 Feb 2017]. Disponible en: 21(4). http://www.medisan.sld.cu/index.php/san/article/view/1064/html 
10. López Jurado S. Auhing Ferrin, K. Prevalencia de enfermedad periodontal en pacientes portadores de prótesis parcial removible en la Clínica de la UCSG A-2016, [citado 9 Feb 2017]. Disponible en: http://repositorio.ucsg.edu.ec/handle/3317/6451

11. Belaúnde M. Relación entre el acceso a la atención dental y el edentulismo en pobladores de 18 a 65 años de edad del distrito de Cajabamba, Provincia de Cajabamba, Departamento de Cajamarca, durante el periodo Febrero - Mayo del 2011. Tesis para Título. Universidad Peruana Cayetano Heredia; 2011

12. López J. Prevalencia de edentulismo parcial según la Clasificación de Kennedy en el Servicio de m Rehabilitación Oral del Centro Médico Naval "Cirujano Mayor Santiago Távara". Tesis para Título. Universidad Nacional Mayor de San Marcos; 2009

13. Awuapara N. Determinación de la asociación entre el edentulismo y la calidad de vida en la población adulta del distrito de Celendín, provincial de Celendín, departamento de Cajamarca en 2010. Tesis para Título. Universidad Peruana Cayetano Heredia; 2010

14. Yeung A, Lo E, Chow T, Clark R. Oral health status of patients 5-6 years after placement of cobalt- chromium removable partial dentures. J Oral Rehabil. 2000; 27(3):183

15. Akaltan F, Kaynak D. An evaluation of the effects of two distal extension removable partial denture designs on tooth stabilization and periodontal health. J Oral Rehabil. 2005;32:823-9 
